\title{
FORCES UNDER THE FOOT
}

\author{
J. R. R. Stott, W. C. Hutton and I. A. F. Stokes, London, England \\ From the Polytechnic of Central London and the Westminster Hospital, London
}

One of the earliest recorded attempts at measuring the pressure distribution under the foot was made by Beely (1882). The subject stepped on a thin bag filled with plaster-of-Paris and the depth of the foot impression was studied. The result of such a method reflects not only the pressure under the foot, but also its shape.

The kinetograph described by Morton (1935) provided a semi-quantitative method. A rubber mat with triangular section corrugations was overlaid with an inked fabric and a layer of paper. As the subject walked on this, an imprint of the corrugations was formed on the paper, and the width to which the corrugations had been deformed gave a measure of the maximum load sustained. Elftman (1934) used a similar principle with a rubber mat laid on a glass plate, the upper surface of the mat being smooth and the lower surface having pyramidal projections. As the subject walked over the mat, the deformation of the apices of the pyramids against the glass was cinephotographed and gave a measure of the load carried by the foot at different phases during the walking cycle.

More recently, capacitance pressure transducers have been inserted into specially constructed shoes (Holden and Muncey 1953). Total loads on the heel were measured and the load against time profile was photographed from an oscilloscope.

Barnett (1954) studied the phases of human gait by means of a pedograph consisting of 3 -inch square section Perspex rods standing on end on a thick slab of sponge rubber: 640 rods were arranged to form a block having an upper surface 6 inches by 15 inches. The displacement of each rod was recorded photographically as the subject stepped on to the block. This displacement under some areas of the foot was more than $\frac{1}{4}$-inch, which would result in a more uniform distribution of load on the sole of the foot than when walking on a rigid surface.

Bauman and Brand (1963), and Schwartz and Heath (1949) attached pressure transducers to the sole of the bare foot. Although pressure transducers slightly distort the sole of the foot, and may by their presence alter the subject's gait, Bauman and Brand pointed out the advantage of their use to measure the loads on the foot inside the subject's normal footwear.

The method described in this report requires no attachments to the foot. The subject walks barefoot on to a firm load-sensitive area at his normal walking speed.

\section{MATERIALS AND METHODS}

The apparatus (Hutton and Drabble 1972) consists of twelve beams each 1.4 centimetres wide by 25 centimetres long, attached at each end through a pin joint to a load cell in turn pin-jointed to a support frame. These dimensions were chosen after considering economy and resolution. Each beam is therefore suspended from two load cells, each of which has four strain gauges. The eight gauges for each beam are wired and orientated to measure only longitudinal tension. Bending and torsion effects are cancelled out.

Each beam, with its two load cells, is connected to an oscillator-amplifier-demodulator system, the output of this being fed on to one channel of a twelve-channel U.V. recorder, which gives a trace of galvanometer deflection against a base of time. The amplifier gains for each beam are set so that each gives the same galvanometer deflection for a known static load. The system is calibrated statically and has a natural frequency of $400 \mathrm{~Hz}$. The 
galvanometer deflection for each beam is dependent only on the magnitude of the vertical load on that beam; it is not dependent on the location of the load.

The twelve support frames are bolted together and the twelve beams form a load-sensitive area (or force plate) 25 centimetres by 17 centimetres (Fig. 1). This force plate is mounted in a square inset fitted centrally into a walkway ( 7 metres long by 75 centimetres wide), so that the subjects can step on and off the force plate during their normal walking cycle. The inset complete with force plate can be removed from the walkway and turned horizontally
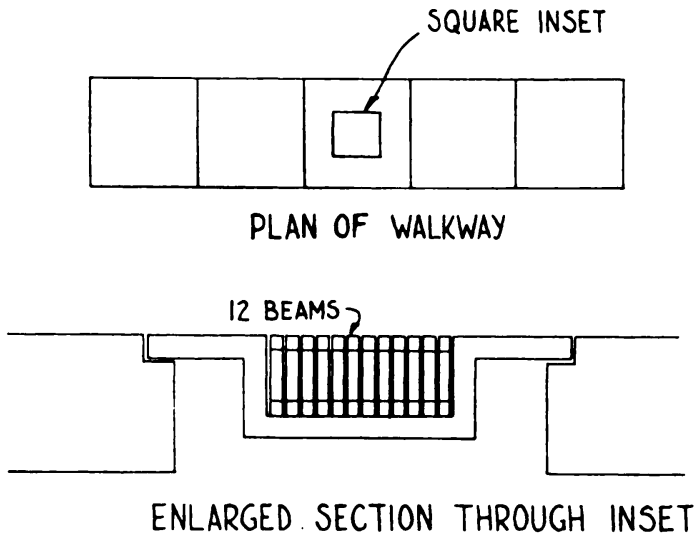

Fig. 1

Diagram showing the square inset which carries the twelve beams of the force plate and which is mounted in the walkway. through 90 degrees, so that the beams can be orientated either transverse or parallel to the direction of walking.

The square inset incorporating the force plate is isolated mechanically from the walkway and rests on the floor. If the square inset is given a sharp tap (equivalent to heel strike) this produces a small galvanometer displacement (representing less than $1 \mathrm{lbf}$ or 4.45 N). This artefact proved extremely useful as a method of determining the instant of heel strike when the heel fell on the square inset but not on the force plate itself.

The exact position of the foot with respect to the beams is recorded for each test. A piece of paper ruled to show the positions of the beams is placed on the force plate. Over this is stretched a piece of fabric with a plastic undersurface, held in position by means of dowels flush with the surface walkway. The plastic surface is coated with printers' ink. The upper fabric surface is painted the same colour as the walkway so that the subject is not aware of the force plate. When he steps on to the fabric, an imprint of his foot is made on the paper.

Each subject was asked to walk without shoes at his normal walking pace. The rate in steps per minute was measured and reproduced on a metronome. All subsequent tests were made at this rate. His pace length was noted, and his starting position on the walkway adjusted so that the desired area of his foot fell on the force plate at his fifth footstep. The subject was asked not to make any deliberate effort to achieve this.

Because of the relatively small surface area of the force plate, it was not possible to accommodate the complete foot during any single test, and at least four tests were necessary to build up a composite load distribution on the whole foot. Tests carried out with the beams transverse to the direction of walking show the longitudinal load pattern under the foot (Fig. 2). With the beams parallel to the direction of walking, either the heel (Fig. 3) or the forefoot (Fig. 4) alone is arranged to fall on the load-sensitive area and the distribution of load across the heel and the forefoot is thus obtained.

\section{RESULTS}

So far, tests have been carried out on fourteen subjects, seven of whom had some foot abnormality.

The recordings shown in Figures 2, 3 and 4 are taken from tests on a patient with hallux valgus, but they illustrate several normal features: 1) the spike of load on the heel seen in Figure 2, beams 1 and 2, as the heel strikes the ground; 2) the low loads measured under the mid-foot, beams 6 to $11 ; 3$ ) the tendency for recordings from the forefoot to show two peaks, the first as the weight of the body is transferred from the heel to the forefoot, and the second 
as the ankle is plantarflexed before the foot leaves the ground. In this patient the loads measured under the big toe are less than those obtained from normal subjects, suggesting

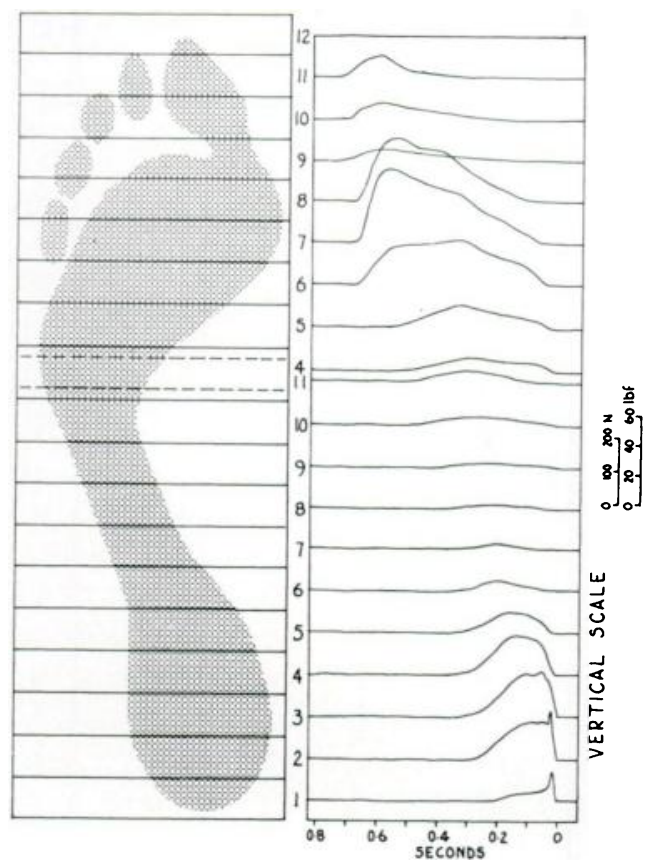

FIG. 2

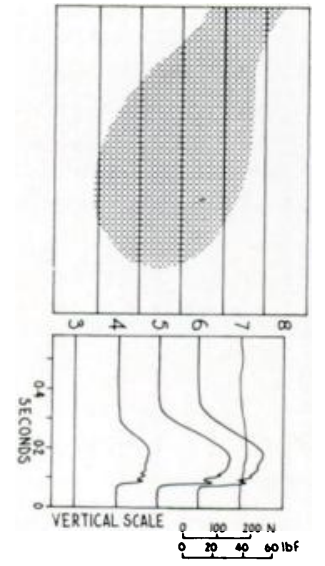

Fig. 3

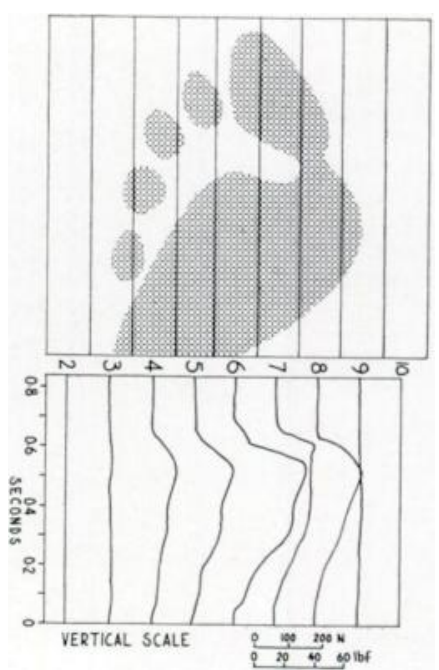

FIG. 4

Figures 2 to 4 are taken from a woman aged 36, height 5 feet 7 inches, weight $126 \mathrm{lbf}$ with bilateral hallux valgus. Figure 2Recordings obtained from two tests with the beams transverse to the direction of walking. Two separate footsteps have been superimposed to build up traces for the whole foot. The low load carried by the midfoot is clearly seen. Figure 3Recordings obtained from the heel, the beams of the force plate being parallel to the direction of walking. Figure 4-Recordings obtained from the forefoot, the beams of the force plate being parallel to the direction of walking.

that when the big toe is deviated laterally it functions less effectively in assisting forward propulsion.

VOL. 55 B, NO. 2, MAY 1973 
Figure 5 shows a graph derived from the recordings of Figure 4 by plotting the highest loads recorded on each beam against their position under the foot. The position of the footprint relative to the beams has been drawn below the graph and the outline of the metatarsal heads added from the radiograph of the foot. It can be seen that the maximum

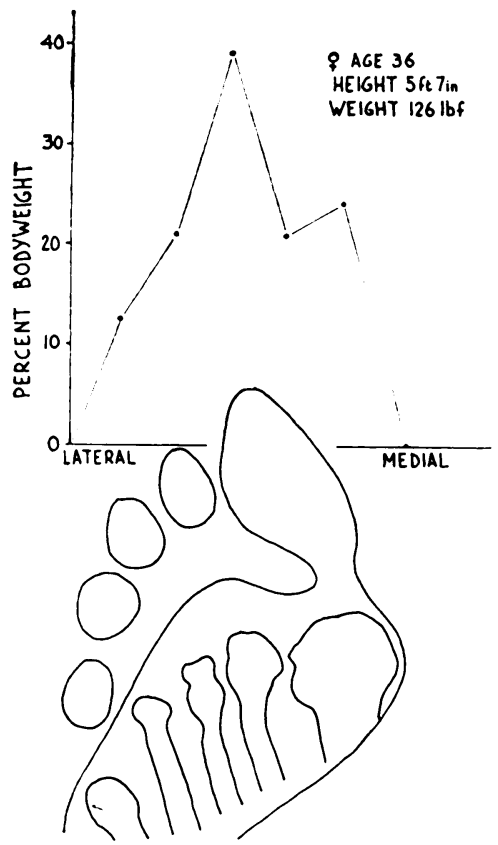

Fig. 5

The distribution of peak loads across the forefoot of a subject with hallux valgus. The footprint is outlined in the correct position relative to the horizontal axis of the graph and the position of the metatarsal heads has been drawn from a superimposed radiograph of the foot. load falls on the second and third metatarsal segments in this patient. Reference is made to this point in a later paragraph.

Preliminary studies to assess the similarity of successive footsteps were done in order to determine the validity of using at least four separate footfalls in building up the load distribution on the whole foot. These repeatability tests were carried out with the beams of the force plate orientated transverse to the direction of walking, and the longitudinal distribution of load on the forefoot was analysed. This area of the foot was chosen because it produces load-time traces which were thought most likely to show up any variation from one footstep to another. Tests of ten successive footfalls of the same subject at his normal walking pace of 108 steps per minute were taken.

The duration of foot contact with the ground varied in the ten tests from 0.68 second to 0.72 second. For each test the load carried by each beam was measured at 35 per cent and 75 per cent of foot contact time. The sum of these measured loads at 35 per cent of foot contact time varied in the ten tests from $103 \mathrm{lbf}(459 \mathrm{~N})$ to $134 \mathrm{lbf}$ $(596 \mathrm{~N})$ (mean $115.7 \mathrm{lbf}$, standard deviation $9.1 \mathrm{lbf}$ ), and at 75 per cent from $187 \mathrm{lbf}(832 \mathrm{~N})$ to $202 \mathrm{lbf}(900 \mathrm{~N})$ (mean $193 \mathrm{lbf}$, standard deviation 4.35 lbf). Graphs were drawn of the load on each beam plotted against the position under the foot, each point along the longitudinal axis corresponding to the midline of a beam. The times of 35 per cent and 75 per cent of foot contact were chosen since traces tended to have maxima at these times. In making the composite graph of all ten tests seen in Figures 6 and 7 the points on the graph of each individual test are offset horizontally relative to those of other tests. This is to allow for the fact that the same area of the foot overlying one beam in one test may in a subsequent test be overlying the adjacent parts of two beams. Provided graphs from the same part of the foot are offset in this way, they can usefully be superimposed and allow some improvement in resolution. Because resolution is limited by the 1.4 centimetre width of the beams, the smooth curve produced from repeated tests, even assuming perfect repeatability, would differ slightly from the true load distribution. Improved resolution would show higher and narrower peaks, wider minima, and a steeper intervening line.

Studies were also carried out to determine the effect on the load distribution of variation in the rate of walking. Figures 8 and 9 show a series of graphs obtained in five tests on the same subject at walking speeds from ninety-two to 126 steps per minute. Results are shown for the tests carried out with the beams orientated parallel to the direction of walking. The highest load recorded by each beam, irrespective of time, is plotted against its position under the heel or the forefoot. For the heel (Fig. 8) there is close agreement in the distribution of peak loads at all walking speeds chosen. In the forefoot (Fig. 9), at walking speeds from 100 to 116 paces per minute, there is good agreement between the graphs. There is discrepancy 
in the shape of the graph at the lowest rate (ninety-two steps per minute), and reduction in the overall height of the graph at the highest walking rate (126 steps per minute). It may be concluded that small variations from the chosen walking rate of experimental subjects will have little effect on the pattern of peak load distribution.

It has been noted that low loads are carried by the midfoot in normal subjects when walking on a rigid surface. The loads for the midfoot are shown in Table I, which gives the

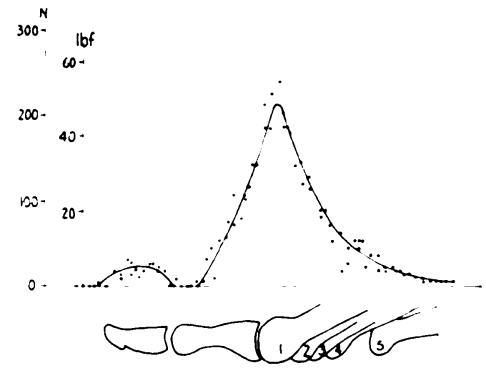

FIG. 6

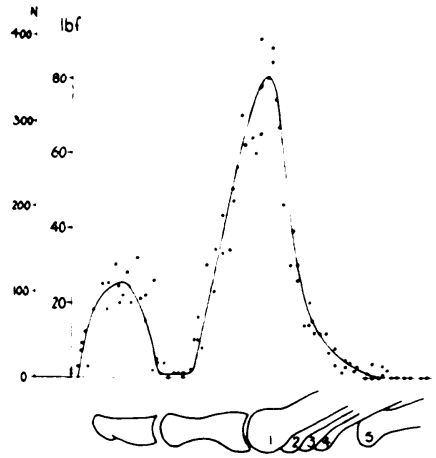

Fig. 7

Scatter graphs showing the longitudinal distribution of load on the forefoot at 35 per cent (Fig. 6) and 75 per cent (Fig. 7) of foot contact time. The results of ten tests on the same subject have been superimposed to assess the repeatability of load distribution from one footstep to another. The bones of the big toe and the metatarsal heads have been drawn in their correct position relative to the horizontal axis by superimposing a radiograph of the foot on the footprints obtained during the tests.

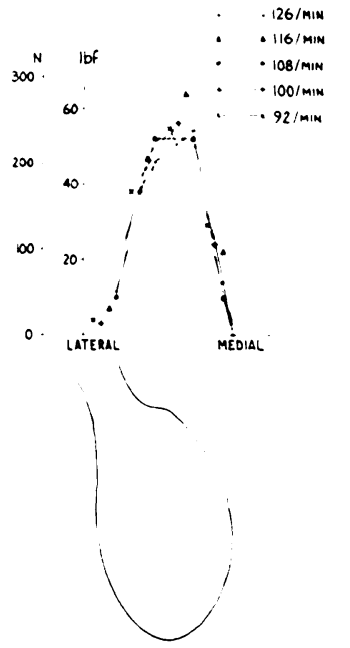

Fig. 8

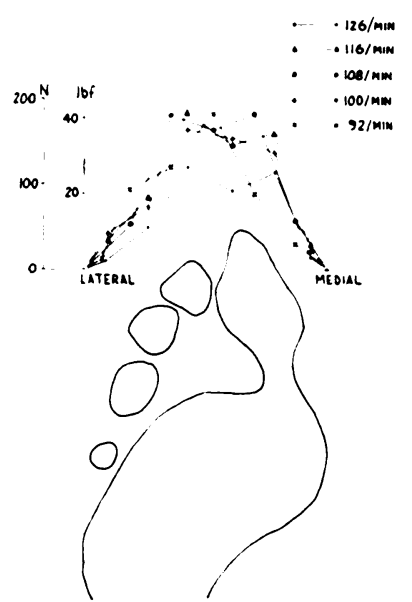

Fig. 9

The distribution of peak loads across the heel (Fig. 8) and the forefoot (Fig. 9) in the same subject at walking speeds from ninety-two to 126 paces per minute. The heel shows a similar pattern at all walking speeds. The forefoot distributes the load more to the lateral side of the foot at the slowest walking rate.

sum of loads measured on four beams of combined width 5.6 centimetres lying transversely under the midfoot. In the normal subjects tested, this load was less than 15 per cent of body weight and below 3 per cent in four subjects. In subjects with flat foot, values of 20.5 per cent (subject 9) and 26 per cent (subject 6) were obtained. In general, the higher the load carried by the midfoot, the greater the peak loads recorded on the lateral side of the forefoot.

VOL. 55 B, NO. 2, MAY 1973 
TABLE I

Detalls of Subjects Tested

Column 8 shows the sum of the loads measured on four adjacent beams lying transversely under the midfoot. This is expressed as a percentage of the subject's weight in column 9.

\begin{tabular}{|c|c|c|c|c|c|c|c|c|c|c|}
\hline \multirow{2}{*}{ Subject } & \multirow{2}{*}{$\begin{array}{l}\text { Sex } \\
\text { Male }\end{array}$} & \multirow{2}{*}{$\begin{array}{c}\begin{array}{c}\text { Age } \\
\text { (years) }\end{array} \\
34\end{array}$} & \multicolumn{2}{|c|}{$\begin{array}{c}\text { Height } \\
\text { feet inches }\end{array}$} & \multirow{2}{*}{$\frac{\begin{array}{c}\text { Weight } \\
(l b f)\end{array}}{156}$} & \multirow{2}{*}{$\begin{array}{c}\begin{array}{c}\text { "Ideal" } \\
\text { weight } \\
\text { (IW Ibf) } \\
\text { (Black } \\
\text { 1968) }\end{array} \\
150\end{array}$} & \multirow{2}{*}{ 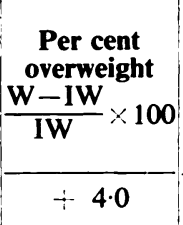 } & \multirow{2}{*}{$\begin{array}{c}\begin{array}{c}\text { Measured } \\
\text { load on } \\
\text { midfoot } \\
(l b f)\end{array} \\
\text { Right } 4.0\end{array}$} & \multirow{2}{*}{\begin{tabular}{|c}
$\begin{array}{c}\text { Load } \\
\text { expressed } \\
\text { as per cent } \\
\text { bodyweight }\end{array}$ \\
$2 \cdot 5$
\end{tabular}} & \multirow{2}{*}{$\begin{array}{c}\begin{array}{c}\text { Foot } \\
\text { abnormality }\end{array} \\
\text { Normal }\end{array}$} \\
\hline & & & 5 & 7 & & & & & & \\
\hline 2 & Male & 32 & 6 & 1 & 139 & 174 & $-20 \cdot 0$ & Right 4.0 & $3 \cdot 0$ & Normal \\
\hline 3 & Male & 40 & 5 & 7 & 145 & 151 & $-4 \cdot 0$ & Right 4.0 & $2 \cdot 8$ & Normal \\
\hline 4 & Male & 50 & 5 & 9 & 150 & 166 & $-9 \cdot 5$ & Right $11 \cdot 0$ & $6 \cdot 5$ & Normal \\
\hline 5 & Male & 25 & 5 & 9 & 142 & 154 & -8.0 & Right 4.0 & $2 \cdot 8$ & Normal \\
\hline 6 & Female & 58 & 5 & 0 & 145 & 133 & +9.0 & Right 38.0 & $26 \cdot 0$ & Right pes planus \\
\hline 7 & Male & 32 & 6 & 1 & 202 & 186 & +8.5 & Right $26 \cdot 0$ & $13 \cdot 0$ & Normal \\
\hline 8 & Male & 50 & 6 & 0 & 199 & 183 & +9.0 & Right 13.0 & $6 \cdot 6$ & Normal \\
\hline 9 & Male & 50 & 5 & 8 & 205 & 161 & $+27 \cdot 0$ & $\begin{array}{l}\text { Right } 42 \cdot 0 \\
\text { Left } 25 \cdot 0\end{array}$ & $\begin{array}{l}20 \cdot 5 \\
12 \cdot 0\end{array}$ & Right pes planus \\
\hline 10 & Female & 36 & 5 & 7 & 126 & 131 & -4.0 & $\begin{array}{l}\text { Right } 7 \cdot 0 \\
\text { Left } 10 \cdot 0\end{array}$ & $\begin{array}{l}5 \cdot 6 \\
8 \cdot 0\end{array}$ & $\begin{array}{c}\text { Bilateral } \\
\text { hallux valgus }\end{array}$ \\
\hline 11 & Female & 26 & 5 & 3 & 129 & 125 & $+3 \cdot 0$ & $\begin{array}{l}\text { Right } 9 \cdot 0 \\
\text { Left } 19 \cdot 0\end{array}$ & $\begin{array}{r}7 \cdot 0 \\
15 \cdot 0\end{array}$ & $\begin{array}{l}\text { Right second } \\
\text { metatarsal pain; } \\
\text { cause unknown }\end{array}$ \\
\hline 12 & Male & 34 & 5 & 7 & 170 & 150 & +13.0 & $\begin{array}{l}\text { Right } 64 \cdot 0 \\
\text { Left } 25 \cdot 0\end{array}$ & $\begin{array}{l}38 \cdot 0 \\
15 \cdot 0\end{array}$ & $\begin{array}{c}\text { Right } \\
\text { varus ankle }\end{array}$ \\
\hline 13 & Female & 56 & 5 & 3 & 121 & 141 & $-14 \cdot 0$ & $\begin{array}{ll}\text { Right } & 8.0 \\
\text { Left } & 8.0\end{array}$ & $\begin{array}{l}6 \cdot 6 \\
6 \cdot 6\end{array}$ & $\begin{array}{l}\text { Rheumatoid } \\
\text { arthritis of feet }\end{array}$ \\
\hline 14 & Female & 50 & 5 & 6 & 156 & 152 & $+2 \cdot 5$ & $\begin{array}{ll}\text { Right } & 7 \cdot 0 \\
\text { Left } & 7 \cdot 0\end{array}$ & $\begin{array}{l}4 \cdot 5 \\
4 \cdot 5\end{array}$ & Hallux rigidus \\
\hline
\end{tabular}

A particularly high load on the midfoot (38 per cent body weight) was found in the right foot of subject 12. Osteomyelitis of the right lower tibia in childhood had resulted in varus

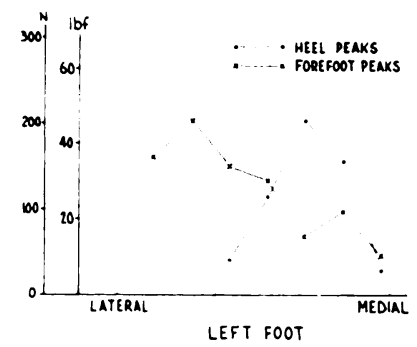

Fig. 10

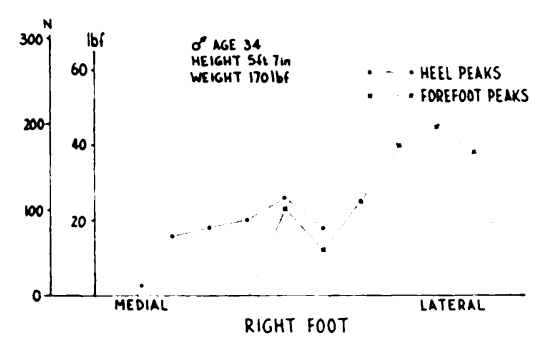

Fig. 11

The distribution of peak loads across the heel and forefoot in a patient with varus deformity of the right ankle (Fig. 11) which had followed osteomyelitis of the lower tibia in childhood. The relative positions of the heel and forefoot graphs indicate the degree of external rotation of the right foot during walking.

deformity of the ankle. Figures 10 and 11 show the peak load distribution across the heel and forefoot in this patient. The abnormal load distribution on the right heel is apparent. 


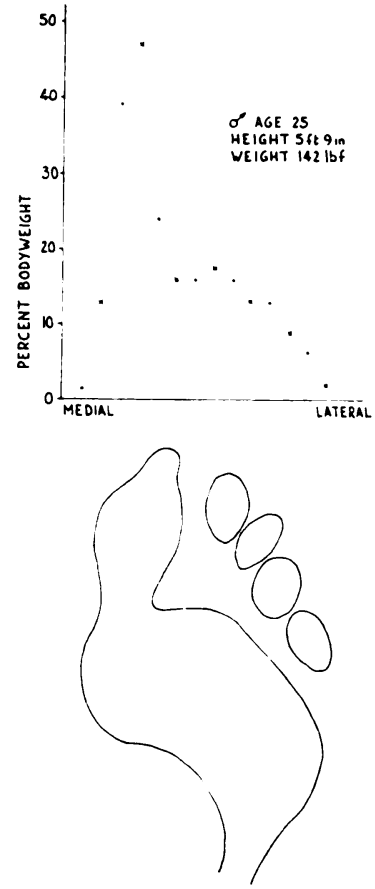

Fig. 12

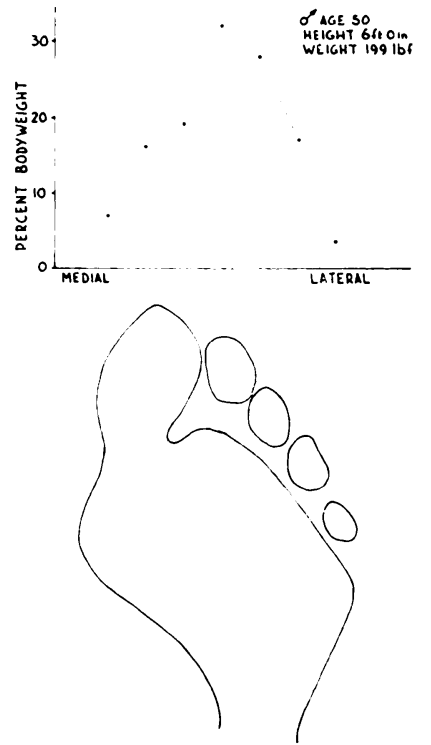

Fig. 14

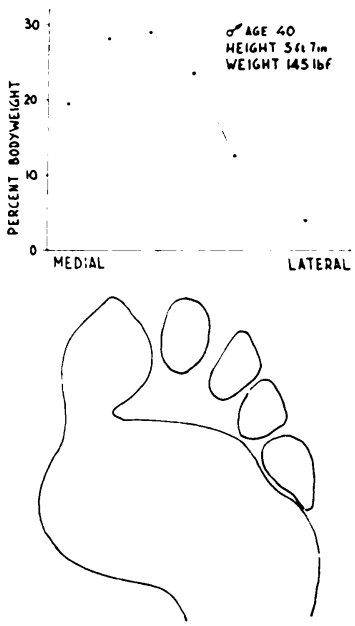

FIG. 13

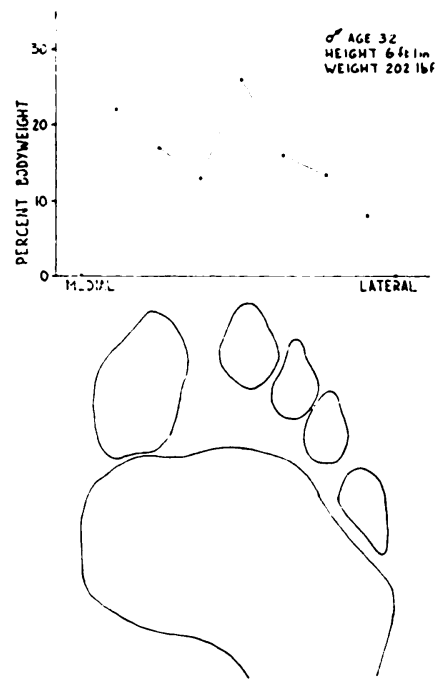

Fig. 15

Figs. 12 To 15

The distribution of peak loads, expressed as a percentage of body weight, on the right forefoot of four normal subjects. Higher body weight is associated with a greater peak load on the lateral side of the foot relative to the medial side. Compare Figures 12 and 13 with Figures 14 and 15.

VOL. 55 B, No. 2, MAY 1973 
The graphs from the forefoot, which are similar in their distribution of peak load, show unusually high peak loads on the lateral metatarsals. This finding is more readily explained in the right foot, in which the lateral side of the heel and midfoot also carry higher loads than normal, but is less expected for the left foot, though the midfoot load of 15 per cent body weight is somewhat high.

The peak load distribution across the heel was very similar for all the normal subjects tested, the maximum load falling just medial to the midline of the heel-print (Fig. 8). The greatest variation between normal individuals is found in the distribution of peak loads across the forefoot. A series of such patterns for some of the normal subjects tested is shown in Figures 12 to 15 . It might be expected that the first metatarsal bone, which is approximately

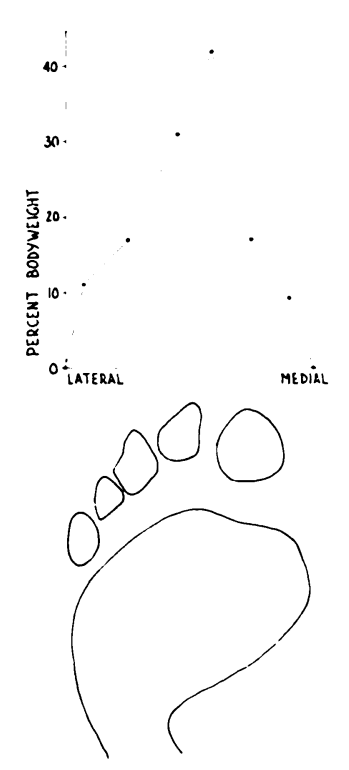

Fig. 16

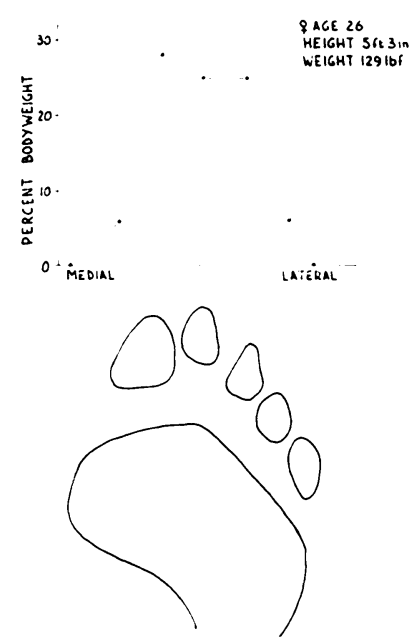

Fig. 17

The distribution of peak load on the forefoot of the left foot (Fig. 16), the right foot (Fig. 17), in a patient with a history of pain in the right second metatarsal bone (see text).

twice the width of the second to fifth metatarsal bones, would carry a commensurate load. This is not always found to be so, a high load falling on the second and third metatarsal bones in some subjects (Figs. 5 and 14). Perhaps stress fractures of the second metatarsal shaft are more likely to occur in such subjects.

A woman aged twenty-six who had a one-year history of pain which developed under the second metatarsal head of the right foot after walking about a mile, showed the peak load distribution of Figures 16 and 17. The pattern from her normal left foot (Fig. 16) showed a peak load of 42 per cent of body weight falling on the second metatarsal segment. In the abnormal foot (Fig. 17) there was no similar peak in this position. The patient admitted having altered her gait after the onset of the pain. It seems that she had done so in such a way as to reduce the stress on a previously heavily loaded second metatarsal bone. Radiographs of the feet showed that the second metatarsal head projected 4 millimetres beyond the first. This relative lengthening of the second metatarsal bone has been noted by Morton (1935) to be a cause of high load and pain under its head.

Further tests were done on two normal subjects to determine the static loads across the forefoot in standing flatfoot, and standing on the toes of one foot. In addition, the peak 
load distribution across the forefoot was measured during sprint running and jumping. The results from the right foot of one of the subjects are shown in Figure 18. In standing flatfoot the load is distributed fairly evenly across the whole forefoot. All the other activities show a generally similar pattern of loading with particularly high peaks during sprint running, almost 100 per cent of body weight in the 1.4 centimetre wide segment under the first metatarsal head. A further point to note in the pattern obtained during running is that the peaks correspond to the first and second metatarsal heads and the trough between these peaks to the gap between these bones. This indicates that the soft tissue intervening between the metatarsal heads and the ground does not even out loads of high magnitude.

\section{CONCLUSIONS}

The method described in this paper of measuring the vertical load on the foot as it falls on a rigid surface is free from the inaccuracies caused by attaching pressure transducers to the foot or by using a load-measuring surface which distorts to a significant extent under load.

The load carried by normal subjects walking on a firm, flat surface is low in the midfoot, ranging from 2.5 per cent to 15 per cent of body weight in this series. Measurement of the load carried by this area of the foot is likely to be of value in the quantitative assessment of conditions such as pes planus or varus deformity of the ankle and their response to treatment.

There is considerable variation in normal subjects in the way maximum loads are distributed across the forefoot during walking. In some, the maximum load falls on the first

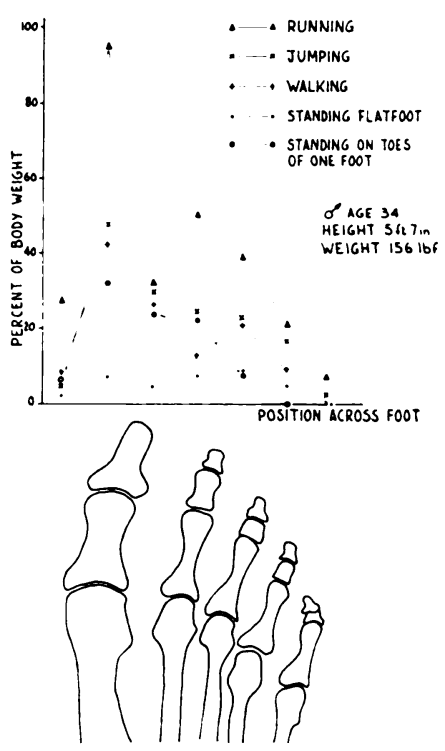

Fig. 18

The distribution of peak loads across the forefoot of a normal subject during the activities listed. The bones of the forefoot are shown in the correct position relative to the horizontal axis. metatarsal segment. In others, this segment of the foot carries low loads compared with the second or third metatarsal bones. The factors determining this distribution remain to be elucidated, though lengthening of the second metatarsal bone relative to the first has been mentioned.

When normal subjects having a high body weight are compared with those of lower body weight, the former carry a greater proportion of load on the lateral side of the forefoot.

When the subject stands still the load is distributed fairly evenly across the forefoot and there is no indication of where the maximum loads occur during walking.

\section{SUMMARY}

1. A method is described for measurement of the vertical load carried by different areas of the foot while walking barefoot. The results of tests on fourteen subjects, seven with some foot abnormality, are reported.

2. The results show that the load carried by the normal midfoot is low. Measurements in this area could be useful in the quantitative assessment of some foot abnormalities.

3. Considerable variation between individuals is seen in the distribution of vertical load across the forefoot. The metatarsal bones do not necessarily carry loads in proportion to their size.

The authors would like to express their thanks to Mr P. H. Newman and Mr D. R. Sweetnam, Middlesex Hospital, London, for allowing them to study patients under their care, to Dr B. Dawson of The Polytechnic of Central London, who advised on some dynamic aspects of the apparatus, and to $\mathrm{Mr} \mathrm{W}$. A. Thornton, also of The Polytechnic, for the drawings.

VOL. 55 B, NO. 2, MAY 1973 
REFERENCES

Barnett, C. H. (1954): A Plastic Pedograph. Lancet, 2, 273.

Bauman, J. H., and Brand, P. W. (1963): Measurement of Pressure Between Foot and Shoe. Lancet, 1, 629.

BeELY, F. (1882): Zur Mechanik des Stehens. Uber die Bedeutung des Fussgewölbes beim Stehen. Langenbecks Archiv für klinische Chirurgie, 27, 457.

Black's Medical Dictionary (1968): Edited by W. A. R. Thomson. Twenty-eighth edition, p. 990. London: Adam and Charles Black Ltd.

Elftman, H. (1934): A Cinematic Study of the Distribution of Pressure in the Human Foot. Anatomical Record, 59, 481.

Holden, T. S., and Muncey, R. W. (1953): Pressures on the Human Foot During Walking. Australiain Journal of Applied Science, 4, 405.

Hutton, W. C., and Drabble, G. E. (1972): An Apparatus to give the Distribution of Vertical Load under the Foot. Rheumatology and Physical Medicine, 11, 313.

Morton, D. J. (1935): The Human Foot. New York: Columbia University Press.

Schwartz, R. P., and Heath, A. L. (1949): The Oscillographic Recording and Quantitative Definition of Functional Disabilities of Human Locomotion. Archives of Physical Medicine, 30, 568. 